\section{Tinjauan Buku}

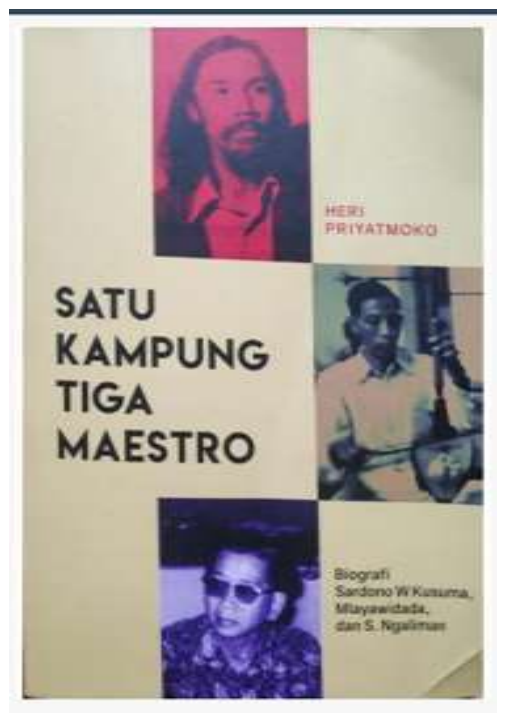

$\begin{array}{lll}\text { Judul Buku } & : \text { Satu Kampung Tiga Maestro: Sardono } \\ & & \text { W. Kusuma, Mlayawidada, } \text { S. } \\ & \text { Ngaliman } \\ \text { Penulis } & : & \text { Heri Priyatmoko } \\ \text { Penerbit } & : & \text { Buku Katta \& Kementerian } \\ & & \text { Pendidikan dan Kebudayaan } \\ \text { Tahun } & : & 2020 \\ \text { Halaman } & : & \mathrm{X}+254 \text { Halaman }\end{array}$

\title{
Satu Kampung Tiga Maestro: Jejak Warisan Budaya di Kota Bengawan
}

Zurab Pololikashvili selaku ketua World Tourism Organization (UNWTO) pada tahun 2018 mengatakan bahwa warisan budaya menceritakan kepada kita yang hidup pada hari ini, mengenai kisah tentang manusia. Kisah ini tergambar dalam berbagai bentuk peninggalan (legacy) yang dapat berupa monumen hingga beragam jenis keunikan ekspresi budaya. E. Potter dan E. A. Modlin, Jr mengatakan bahwa warisan budaya merupakan wujud (benda maupun tak benda) dari rangkaian memori sosial manusia, baik individu maupun kelompok, yang menunjukkan identitas ataupun dapat memberikan identifikasi pada keunikan ataupun kekhasan pengetahuan maupun budaya, serta pengalaman pada masa lalu (Potter dan Modlin dalam Hanna, Porter, Modlin, Carter, dan Butler (eds.), 2015: 4; World Tourism Organization (UNWTO), 2018: i). Konsepsi mengenai warisan budaya pada masa kontemporer saat ini juga telah mempertimbangkan berbagai bentuk kajian-kajian etnografi dan antropologi yang memberikan kesadaran terhadap perlindungan ekspresi, representasi, dan manifestasi kebudayaan individu maupun kelompok (World Tourism Organization (UNWTO), 2018: 19).

Melalui buku "Satu Kampung Tiga Maestro", Heri Priyatmoko (2020) menawarkan satu ulasan menarik mengenai jejak warisan budaya di Kota Surakarta (Solo) dalam fragmen kehidupan para seniman tradisi di Kampung Kemlayan. Heri menghadirkan sebuah gambaran pemukiman menarik yang berada di pusat Kota Solo, yang tidak saja menjadi hunian, namun lebih dalam dari itu, Kampung Kemlayan merupakan padepokan sekaligus ruang ekspresi para seniman yang jejak sejarahnya dapat ditelusuri hingga periode awal renaisans budaya Jawa di Surakarta pada akhir abad ke-18. Pada tulisan di bukunya ini Heri tidak saja menghadirkan memori tentang Kampung Kemlayan yang dikenal pula sebagai Kampung Gamelan atau Kampung Karawitan, namun Heri menghadirkan sosoksosok yang tumbuh dari sejak menjalani proses nyantrik hingga menjadi begawanbegawan seni yang adiluhung baik di Surakarta maupun Tanah Air. Heri menghadirkan 
tiga sosok begawan seni dalam Budaya Jawa maupun Budaya Indonesia yaitu Sardono W. Kusuma, Mlayawidada, dan S. Ngaliman.

Putu Agustiananda (2012) dalam artikelnya mengenai pelestarian budaya di Kota Surakarta mengatakan bahwa warisan budaya di kota ini tidak hanya berupa monumen atau bangunan bersejarah, namun seluruh aspek morfologi perkotaan di Surakarta merupakan kawasan cagar budaya yang harus dilestarikan. Kampung sebagai bagian dari morfologi urban dapat memiliki nilai historis maupun kultural yang kemudian juga dapat dikembangkan sebagai kawasan budaya (heritage). Putu Agustianda selanjutnya mengatakan bahwa di Kota Surakarta terdapat enam kategori kawasan cagar budaya yakni: 1) area atau distrik; 2) bangunan tradisional; 3) bangunan kolonial; 4) bangunan keagamaan; 5) fasilitas umum dan penunjang kawasan kota; serta 6) taman dan ruang terbuka publik. Upaya dalam membangun pemahaman terhadap pentingnya nilai warisan budaya terhadap suatu objek material di suatu kawasan urban adalah dengan melakukan reproduksi memori melalui penyusunan narasi tentang objek tersebut di masa lampau dan pemanfaatannya dalam membentuk karakteristik identitas perkotaan pada masa kini. Persepsi terhadap kategorisasi cagar budaya di Surakarta sebagaimana yang telah disusun oleh Putu Agustiananda akan semakin kuat apabila turut pula disusun narasi pelengkap yang dapat menceritakan kisah mengenai objek material tersebut. Pada tataran inilah kemudian E. Potter dan E.A. Modlin Jr. menegaskan mengenai reproduksi memori pada suatu objek cagar budaya hendaknya perlu dilakukan agar terjalin narasi antara objek materi dengan pengalaman historis yang terbentuk di ruang atau objek material tersebut (Agustiananda, 2012: 28-29; Potter dan Modlin dalam Hanna, Porter, Modlin, Carter, dan Butler (eds.), 2015: 5).

Proses reproduksi memori tentang Kampung Kemlayan inilah yang hendak disampaikan oleh Heri Priyamoko (2020) dalam bukunya. Buku yang terdiri atas enam bab ini menawarkan empat kisah menarik yakni tentang ekologi budaya di Kampung Kemlayan dan mengenai individu-individu yang berperan dalam membentuk dan mempertahankan identitas Kampung Kemlayan sebagai kampung Seni Karawitan Jawa. Proses reproduksi memori Kampung Kemlayan dikisahkan oleh Heri Priyatmoko di dalam bab kedua buku ini. Pada bab ini Heri bercerita mengenai ekosistem budaya di Kampung Kemlayan yang khas sebagai kampung para seniman penabuh gamelan sejak masa pemerintahan Sunan Pakubuwono IV dari Surakarta yang bertahta sejak 1768 hingga 1820. Pada bagian ini Heri bercerita mengenai formasi sejarah di Kampung Kemlayan beserta dengan dinamika dari rangkaian peristiwa yang terjadi di kampung ini.

Heri melihat bahwa telah terjadi konvergensi antara lingkungan Kampung Kemlayan dengan munculnya para individu seniman yang kemudian dapat tumbuh hingga menjadi begawan-begawan seni terkemuka. Suasana kampung yang selalu semarak dengan tabuhan gamelan telah membentuk anak-anak di Kemlayan untuk mengakrabi seni sejak usia dini. Proses regenerasi yang berlangsung sejak akhir abad ke-18 telah menciptakan identitas bagi masyarakat di kampung ini. Heri menunjukkan beragam realitas sosial yang menggambarkan bahwa telah terjadi proses berkesenian yang telah berlangsung secara berkelanjutan selama beberapa generasi. Kampung Kemlayan meskipun lekat dengan jejak feodalisme karena para seniman karawitan ini pada masa sebelum kemerdekaan merupakan para abdi dalem sekaligus priayi, namun mampu menghadirkan keragaman budaya yang lebih egaliter. Dengan keragaman budaya yang lebih egaliter itu, mereka mampu bersinergi untuk menghasilkan bentuk kesenian sesuai dengan permintaan dari budaya massa yang berkembang pada masa sesudah kemerdekaan di Surakarta. 
Gambaran yang disampaikan oleh Heri pada bab kedua inilah yang kiranya menunjukkan bahwa Kemlayan bukan sekadar kampung hunian semata. Proses reproduksi memori terhadap beragam aspek sosial dan budaya yang disajikan oleh Heri juga menjadi modal penting bagi upaya pelestarian Kampung Kemlayan sebagai salah satu cagar budaya di Kota Surakarta. Seni yang berkembang di Kampung Kemlayan tidak lantas berhenti seiring dengan memudarnya konsumsi langgam Jawa pada masyarakat saat ini. Kemlayan rupanya pada saat ini tidak lantas bertransformasi mengikuti arus budaya massa, namun melalui kehadiran kembali sosok maestro tari Sardono W. Kusumo, Kemlayan tetap menghadirkan bentuk budaya yang adiluhung berpendar dari panggung dan studio tari milik Sardono W, Kusumo. Identitas sebagai kampung budaya dan seniman masih melekat hingga kini, tentu tidak berlebihan bahwa kemudian Heri menyebut bahwa Kemlayan merupakan salah satu pilar budaya Surakarta. Alasan inilah yang kerap membuat Heri yang juga merupakan salah satu penggiat di komunitas pencinta sejarah dan budaya di Kota Solo, yaitu Solo Societiet kerap mengajak anak muda untuk datang, singgah, dan mendengarkan dongeng tentang Kemlayan. Memori sosial ini hadir tidak saja dalam bentuk material jejak budaya, namun juga hadir dalam narasi, tabuhan gamelan, dan gerak tari yang masih kerap ditemui di kampung itu.

Pada bab tiga dalam bukunya, Heri mengajak pembaca untuk masuk ke dalam ruang semesta begawan tari Sardono W. Kusumo. Menampilkan sosok-sosok budayawan dan seniman seperti Sardono, Mlayawidada, dan S. Ngaliman dalam pembahasannya mengenai Kemlayan, memberikan penguatan terhadap narasi memori sosial tentang keberadaaan Kemlayan sebagai esensi penting dalam pembahasan mengenai situs warisan budaya di Kota Bengawan. Membahas mengenai situs budaya hendaknya tidak saja melihatnya dalam esensi ruang dan materi. E. Potter dan E.A. Modlin Jr. sekali lagi memberikan suatu gambaran bahwa bagaimana kehadiran dan pengalaman individu yang berada di dalam ruang ataupun situs budaya akan memberikan suatu nilai dan pemahaman yang lebih luas mengenai arti dan esensi makna terhadap objek warisan budaya tersebut kepada para pengunjung yang singgah (Potter dan Modlin dalam Hanna, Porter, Modlin, Carter, dan Butler (eds.), 2015: 5).

Sardono W. Kusumo yang dipaparkan oleh Heri dalam bab ketiganya ini merupakan sosok Sardono yang telah kembali pulang ke Kemlayan dari perjalanannya yang panjang dalam berkesenian. Sardono di dalam catatan Heri ini hendak menghidupkan kembali kehidupan berkesenian di Surakarta yang ia mulai dari studio tarinya di Kemlayan. Sardono ingin menghidupkan kembali gairah berkesenian di Surakarta seperti pada masa Sunan Pakubuwono X dan Pangeran Mangkunegara VII, ketika Surakarta masyhur sebagai pusat kebudayaan Jawa. Melalui Kemlayan, Sardono hendak menghidupkan kembali ruang-ruang sejarah di Kota Surakarta yang telah ditinggalkan untuk kembali lestari sebagai ruang publik dan berkesenian. Pengalaman panjang Sardono yang mulai belajar menari dari alunan tabuhan gamelan di Kemlayan hingga menjadi Guru Besar di Institut Kesenian Jakarta (IKJ) menjadi modal utama dalam menghidupkan kembali Solo sebagai The Spirit of Java. Melalui upaya yang dilakukan oleh Sardono serta para pemerhati dan pelaku budaya di Kota Solo, Kampung Kemlayan kembali dihidupkan melalui berbagai narasi memori sosial dan budaya, serta menjadi ruang ekspresi berkesenian. Kampung Kemlayan oleh Sardono dan rekan-rekan tetap dipertahankan sebagai kampung para seniman meski para seniman karawitan yang bermukim di Kemlayan kini mulai hilang, namun keberadaan studio Sardono dan aktivitas berkesenian yang dilakukan oleh murid-muridnya tetap berlangsung. Hal inilah kiranya yang diharapkan kembali bahwa di Kemlayan dapat melahirkan kembali para maestro seni terkemuka di Indonesia. 
Pada bab keempat dan kelima, Heri bercerita tentang Mlayawidada dan S. Ngaliman. Kedua maestro dalam seni karawitan dan seni tari ini dianggap sebagai begawan terakhir yang menyemarakkan kehidupan berkesenian di Kraton Surakarta Hadiningrat maupun Kota Solo. Kedua seniman ini berada pada fase peralihan sejarah dari masa Kasunanan Surakarta ke masa Republik Indonesia yang merdeka. Mereka kini tidak hanya mencari nafkah di lingkungan keraton, namun juga turut berkarya dalam ruang publik yang lebih luas baik di panggung hingga studio RRI dan TVRI. Pembahasan Heri mengenai kedua tokoh ini memberikan suatu perspektif menarik dalam masa-masa awal kemerderkaan. Heri menghadirkan kisah tentang bagaimana para seniman ini harus berjuang untuk bertahan dengan kemampuan kesenian yang mereka miliki pada fase-fase yang penuh gejolak; pada masa revolusi hingga dua dekade awal masa kemerdekaan.

Fragmen sejarah mengenai bagaimana seni keraton kemudian berkembang menjadi konsumsi publik secara tidak langsung juga diungkapkan oleh Heri. Melalui apa yang dikisahkan oleh Heri ternyata ada fase yang menarik dalam sejarah kebudayaan di Indonesia tentang bagaimana seni keraton yang adiluhung kemudian mengalami transformasi menjadi budaya massa namun tanpa harus mengubah esensi tradisi (pakem) yang menjadi jiwa dari seni tersebut secara revolusioner. Para seniman di Kemlayan rupanya mampu tampil dengan menyesuaikan diri pada perkembangan zaman serta selera masyarakat tanpa harus kehilangan identitas mereka sebagai empu budaya tradisi sekaligus seniman-priayi yang terhormat. Melalui buku setebal 254 halaman ini Heri Priyamoko telah menjadikan Kampung Kemlayan sebagai sebuah ruang pusaka (heritage landscape) yang kaya akan rangkaian memori sosial dan budaya.

\section{(G. Andika Ariwibowo)}

\section{Daftar Pustaka}

Agustiananda, Putu. (2012).

Urban Heritage Conservation in Surakarta, Indonesia: Scenarios and Strategies for the Future. International Journal of Civil \& Environmental Engineering IJCEE-IJENS Vol: 12 No: 02. (hlm. 28-35)

Potter. Amy E. dan Modlin, Jr. E. A. (2015).

Introduction dalam Stephen P. Hanna, Amy E. Potter, E. Arnold Modlin, Jr., Perry Carter, dan David L. Butler. (2015). Social Memory and Heritage Tourism Methodologies. New York: Routledge. (hlm. 1-11).

World Tourism Organization (UNWTO). (2018).

Tourism and Culture Synergies. Madrid: UNWTO 